\title{
Effect of Water on Bonding of One-bottle Self-etching Adhesives
}

\author{
Masanori HASHIMOTO $^{1}$, Shinichi FUJITA ${ }^{1}$, Masayuki KAGA ${ }^{2}$ and Yasutaka YAWAKA ${ }^{2}$ \\ ${ }^{1}$ Division of Biomaterials and Bioengineering, School of Dentistry, Health Sciences University of Hokkaido, 1757 Kanazawa, \\ Ishikari-Tobetsu, Hokkaido 061-0293, Japan \\ ${ }^{2}$ Department of Pediatric Dentistry, Graduate School of Dental Medicine, Hokkaido University, Kita 13, Nishi 7, Kita-ku, \\ Sapporo, Hokkaido 060-8586, Japan. \\ Corresponding author, Masanori HASHIMOTO; E-mail: masanori-h@mue.biglobe.ne.jp
}

Received July 18, 2007/Accepted September 10, 2007

\begin{abstract}
This study evaluated the effect of water on dentin substrate bonding of one-bottle self-etching adhesives. Dentin substrates were divided into two groups: wet and dry dentin. Wet dentin is the normal substrate for bond testing whereas dry dentin was dehydrated in a desiccator for 24 hours. Bonded dehydrated teeth were then divided into two subgroups: stored in water or in desiccator for 24 hours. Microtensile bond strength of resin to dentin was measured using three one-bottle self-etching adhesives. In addition, nanoleakage evaluation was performed through the analyses of SEM and TEM micrographs. The bond strength of dry-dentin group was significantly greater than that of wet-dentin. Further, the amount of nanoleakage within the adhesive interface of dry-dentin group was less than that of wet-dentin. Results showed that bond strength and nanoleakage formation depended on the bonding substrate (wet versus dry dentin) before bonding. One-bottle self-etching adhesives might suck the water from dentinal tubules during bonding by osmosis, leading to nanoleakage formation and thus a decline in bond strength.
\end{abstract}

Keywords: One-bottle resin adhesive, Bond strength, Electron microscopy, Degradation

\section{INTRODUCTION}

Self-etching adhesive systems are currently available as two-step and single-step types, according to the number of clinical steps associated with the application of the adhesive resin. Single-step self-etching systems can be further divided into all-in-one or onebottle type, depending on whether mixing is required. Recently introduced all-in-one adhesives are supplied as two bottles that must be mixed together immediately before use. As for one-bottle self-etching systems, they have been developed with a view to further simplifying the bonding procedure. With one-bottle self-etching adhesives, one drop of bonding resin from one container is applied to the tooth cavity, and the subsequent bonding steps entail resin application, air blasting, and light curing. In other words, one-bottle self-etching adhesives enable the multiple steps of etching, priming, and bonding to be done simultaneously.

Several studies have shown that water trees, water bubbles, and phase separation occurred in the adhesive interface of all-in-one and one-bottle adhesives $^{1-4)}$. These occurrences are not typical for traditional hydrophobic adhesives (i.e., three-step etch-and-rinse or two-step self-etching adhesives). Furthermore, the amount of nanoleakage within the bonding resin layer is large for one-step self-etching adhesives due to their increased concentrations of water and solvent (acetone or ethanol) ${ }^{5,6}$.

Water is an essential component for demineralization of dentin hard tissue by the acidic monomer, while acetone and ethanol act as cosolvents with water for resin. However, the hydrophilic nature of bonding resins makes them vulnerable to water absorption and leaching of water-soluble hydrophilic monomers permits water movement across the bonding resin even after curing ${ }^{7,8}$. Indeed, where nanoleakage formation is present, water is present at the bonding interface.

In several recent reports, where caries-affected dentin, dehydrated dentin, and cured resin composite were used as bonding substrates, it was found that minimal nanoleakage occurred within the resin-dentin interface ${ }^{9,10)}$. On the effect of the hydration condition of tooth substrates on bond strength, an all-inone self-etching adhesive (One-Up Bond F) was used in a previous study to examine the effects of pre- and post-bonding hydration on bond strength to dentin ${ }^{11}$. This study concluded that post-bonding water exposure (i.e., water storage after bonding) significantly reduced bond strength as compared to that of dry storage after bonding. However, since the current generation of one-bottle self-etching adhesives are more hydrophilic, different findings might be yielded.

Therefore, the objective of this study was to evaluate the effect of water on the dentin surface on bond integrity of three one-bottle adhesive resins (selfetching systems) using microtensile bond strength test, SEM, and TEM. The null hypothesis tested was that there is no difference in bond strength or nanoleakage distribution for wet and dry dentin substrates. 


\section{MATERIALS AND METHODS}

Test groups and one-bottle self-etching adhesives

Forty-five unerupted human third molars were collected after obtaining the patients' informed consent under a protocol reviewed and approved by the institutional review board of Hokkaido University. The teeth were used within two months following extraction. Each tooth was sectioned perpendicular to its longitudinal axis using a diamond disk (Isomet, Buehler Ltd., Lake Bluff, IL, USA) under a stream of water to expose a flat dentin surface (mid-coronal portion). Each surface was ground with 600-grit silicon carbide paper under running water for 30 seconds just prior to bonding.

The dentin substrates were divided into three groups: (1) wet dentin in water (control: resin bonding was performed immediately after polishing the dentin, and resin-dentin bonded specimens were stored in water for 24 hours as per the normal specimen preparation procedure for bond testing); (2) dry dentin in dry condition (dentin was kept in a desiccator for 24 hours and then for 24 hours after bonding); (3) dry dentin in water (dentin was kept in a desiccator for 24 hours and then for 24 hours in water after bonding).

Three one-bottle self-etching adhesives (Clearfil $\mathrm{S}^{3}$ Bond, Kuraray; G-Bond, GC; and iBond, Heraeus
Kulzer) were used in this study (Table 1). Each bonding resin was applied on the dentin surface according to manufacturer's instructions (Table 1). Following adhesive treatment, five 1-mm increments of a resin composite (AP-X, Kuraray Co. Ltd., Osaka, Japan) were built up and individually light-activated for 60 seconds for the microtensile bond strength test and SEM examination. For TEM analysis, an approximately $1-\mathrm{mm}$ resin composite (Protect Liner F, Kuraray Co. Ltd.) was applied on the resin-bonded dentin surface prepared as previously described. The resin-dentin bonded specimens were stored in two different conditions as previously described.

\section{Microtensile bond test}

After 24 hours in water, the samples were cross-sectioned perpendicular to the adhesive interface with a diamond saw to produce beams (adhesive area: approximately $0.9 \mathrm{~mm}^{2}$ ) under water cooling/lubrication. The six beams were obtained from the center portion of resin-dentin bonded teeth. The beams were then attached with a cyanoacrylate adhesive to a testing apparatus, and a tensile load was applied with a material tester (EZ Test, Shimadzu, Kyoto, Japan) at a crosshead speed of $1.0 \mathrm{~mm} / \mathrm{min}$. Any beam that failed during specimen preparation (such as the sectioning or fixation process) was recorded as $0 \mathrm{MPa}$ bond strength. Mean bond strengths were

Table 1 Chemical formulations and bonding procedures of the three self-etching one-bottle adhesives tested

\begin{tabular}{|c|c|c|c|}
\hline Adhesive(manufacture) & Chemical formulations & Resin application & Air-blast \\
\hline $\begin{array}{l}\text { G-Bond } \\
\text { (GC, Kyoto, Japan) }\end{array}$ & $\begin{array}{l}\text { methacrylate, phosphoric acid esters, } \\
\text { 4-MET, UDMA, acetone, water }\end{array}$ & $\begin{array}{l}\text { Apply to tooth } \\
\text { for } 10 \text { seconds }\end{array}$ & $\begin{array}{l}\text { Strong air-blast } \\
\text { for } 3 \text { seconds }\end{array}$ \\
\hline $\begin{array}{l}\text { iBond } \\
\text { (Heraeus Kulzer, } \\
\text { Hanau, Germany) }\end{array}$ & $\begin{array}{l}\text { 4-META, UDMA, glutardialdehyde, } \\
\text { acetone, water }\end{array}$ & $\begin{array}{l}\text { Apply to tooth } 3 \text { times } \\
\text { during } 30 \text { seconds }\end{array}$ & $\begin{array}{l}\text { Strong air-blast after } \\
\text { gentle air-blast }\end{array}$ \\
\hline $\begin{array}{l}\mathrm{S}^{3} \text { Bond } \\
\text { (Kuraray, Osaka, Japan) }\end{array}$ & $\begin{array}{l}\text { MDP, Bis-GMA, HEMA, ethanol, } \\
\text { water }\end{array}$ & $\begin{array}{l}\text { apply to tooth for } \\
20 \text { seconds }\end{array}$ & $\begin{array}{l}\text { Strong air-blast } \\
\text { for } 5 \text { seconds }\end{array}$ \\
\hline
\end{tabular}

\footnotetext{
Abbreviations:

Bis-GMA: bisphenol-glycodyl methacrylate

HEMA: 2-hydroyxylethyl methacrylate

MDP: 10-methacryloyloxydecyl dihydrogen phosphate

UDMA: urethane dimethacrylate

4-MET: 4-acryloxyethyl trimellitic acid

4-META: 4-methacryloxyethyl trimellitate anhydride
} 
evaluated by two-way ANOVA and Fisher's PLSD test $(\mathrm{p}<0.01, \mathrm{p}<0.05, \mathrm{n}=18-22$ for each group).

\section{SEM fractography}

After bond testing, the dentin side of the beam was immediately fixed in $2.5 \%$ glutaraldehyde in $0.1 \mathrm{M}$ cacodylate buffer titrated to $\mathrm{pH} 7.2$ for 72 hours and then rinsed several times with $0.1 \mathrm{M}$ sodium cacodylate buffer. The beams were dehydrated in increasing concentrations of ethanol $(40,50,60,70,80$, and $90 \%$ ) for 30 minutes each and in 100\% ethanol for 24 hours. Final chemical drying was conducted according to the protocol of Perdigão et al. ${ }^{12)}$ using hexamethyldisilazane (Kyouwa Chemicals, Tokyo, Japan). The dentin side of the fractured beam was sputter-coated with gold and then analyzed in a field-emission scanning electron microscope (S-4000, Hitachi Ltd., Tokyo, Japan) at an acceleration voltage of $10 \mathrm{kV}$.

\section{TEM examination}

Resin-dentin bonded specimens for TEM were prepared as $1 \times 2 \times 4 \mathrm{~mm}$ slabs and immersed in a 50 $\mathrm{w} / \mathrm{v} \%$ ammoniacal silver nitrate solution, according to a protocol described by Tay and Pashley ${ }^{13)}$. The resin-dentin bonded specimens were then fixed, dehydrated and embedded in an epoxy resin (TAAB 812 resin, TAAB Laboratories, Aldermaston, UK) at $60^{\circ} \mathrm{C}$ for 120 hours. After resin embedding, 90- to 100$\mathrm{nm}$-thick ultrathin sections were cut with a diamond knife (Diatome, Bienne, Switzerland) using an ultramicrotome (Ultracut UCT, Leica, Vienna, Austria) and then collected onto 200 mesh copper grids. After drying without staining, the sections were observed with a TEM (H-800, Hitachi) operated at $80 \mathrm{kV}$. Six sections were examined for each group.

\section{RESULTS}

Figure 1 shows the mean bond strength of each group. For the control group, the order of the bond strengths of the adhesives was $\mathrm{S}^{3}$ bond $(40 \pm 12 \mathrm{MPa})$ $>$ G-Bond $(31 \pm 11 \mathrm{MPa})>$ iBond $(18 \pm 15 \mathrm{MPa})$ with significant differences $(p<0.05)$. As for the bond strengths of the three adhesive systems that were dry-bonded and stored in dry condition, they were significantly greater than the control $\left(p<0.05\right.$ for $\mathrm{S}^{3}$ bond, $\mathrm{p}<0.01$ for G-Bond and iBond). No significant differences in bond strength were found among the adhesives for dry bonding and storage in the dry condition $(p>0.05)$. With the iBond specimens, four pre-testing failures were recorded for the control group and which were included in the analysis as 0 $\mathrm{MPa}$. However, many specimens broke during specimen preparation in the group with dry bonding and storage in water. In the same connection, the bond strength of this group was significantly lower than

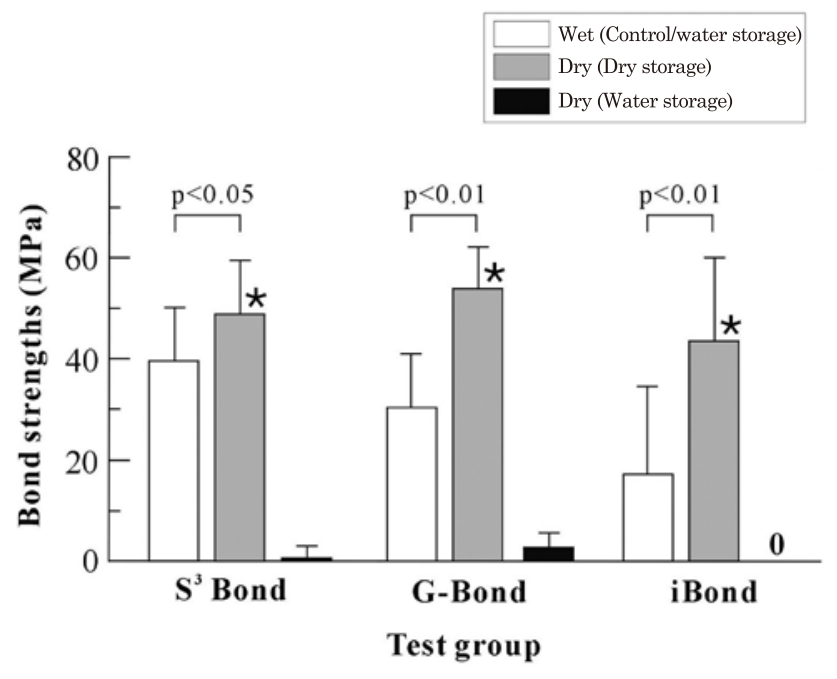

Fig. 1 Microtensile bond strength (mean \pm standard deviation) of each test group. Groups with bond strengths that were not significantly different $(p>0.05)$ are indicated by an asterisk (*). Data were analyzed using two-way ANOVA and Fisher's PLSD test $(\mathrm{p}<0.01, \mathrm{p}<0.05, \mathrm{n}=18-22$ for each group).

the other groups $(\mathrm{p}<0.01)$.

Figure 2 shows the SEM micrographs of adhesive failure of G-Bond (Figs. 2a-c), iBond (Figs. 2d-f), and $\mathrm{S}^{3}$ Bond (Figs. 2g-i). Numerous balloon-shaped voids extended into the bonding resin layer for all the control specimens (Figs. 2a, 2d, and 2g). For GBond, bubbles of varying sizes were found in all the test groups (Figs 2a-c). However, no bubble formation was detected in the dry-dentin group for iBond (Figs. 2e and 2f) and $\mathrm{S}^{3}$ Bond (Figs. 2h and 2i).

TEM analysis revealed extensive silver staining within the hybrid layer and bonding resin layer in the control specimens bonded with iBond (Fig. 3a). However, the silver staining was very limited in the dry specimens (Figs. $3 b-d$ ), where sporadic spot-mode regions of nanoleakage were found in the hybrid layer or bonding resin layer (Fig. 3d). There was less nanoleakage formation within the hybrid layer in the control specimens of $\mathrm{S}^{3}$ Bond (Fig. 4a) and G-Bond (Fig. 4c) than for iBond (Fig. 3a). In addition, the silver staining was very sporadic in the specimens of the dry-dentin groups (Figs. $4 \mathrm{~b}$ and 4d). Bubble formation in the bonding resin layer was found in all groups for G-Bond (Figs. 4c and 4d). 

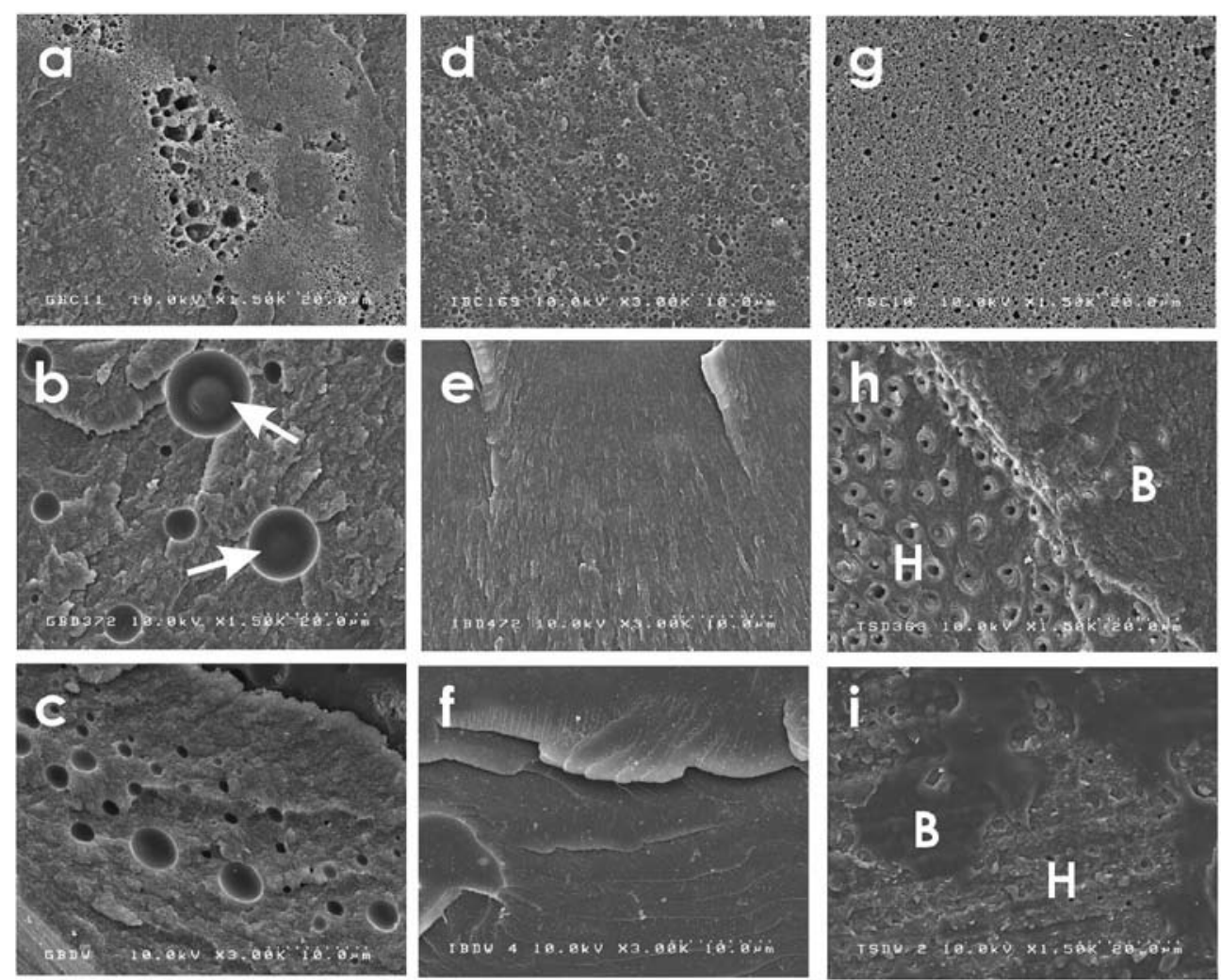

Fig. 2 SEM micrographs of the fractured surfaces of the dentin side of specimens for each adhesive (a-c: G-Bond, $\mathrm{d}-\mathrm{f}$ : iBond, g-i: $\mathrm{S}^{3}$ Bond; a,d, and g: control, b, e, and h: dry dentin in the desiccator, c, f, and i: dry dentin in water). For G-Bond, varying-sized water bubbles were observed in the bonding resin layer for all groups. For all adhesives, nanoleakage expression in spotted mode was detected in all the control specimens (a, d, and g). However, nanoleakage was very limited in the adhesive layer in the dry-dentin group (dry dentin in the desiccator or in water) for iBond (e and $\mathrm{f}$ ), and $\mathrm{S}^{3}$ Bond (h and i). White arrows indicate water bubbles. B: Bonding resin, H: Hybrid layer.
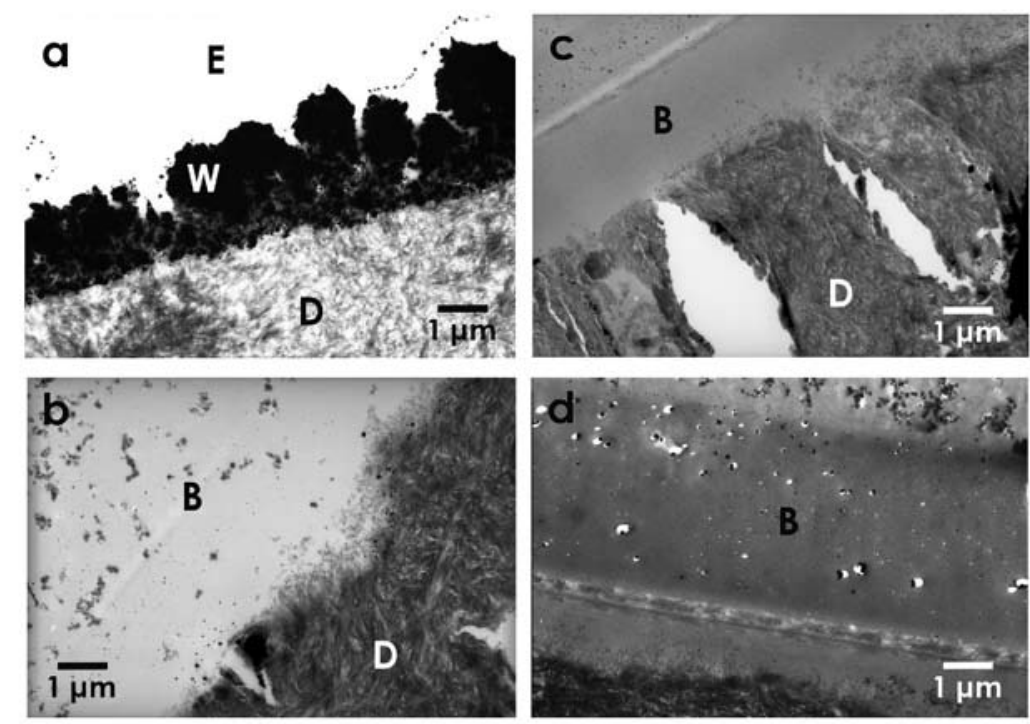

Fig. 3 TEM micrographs of the resin-dentin interface in the following specimens of iBond: (a) control, (b) dry dentin in desiccator, and (c, d) dry dentin in water storage. Strong silver staining (water tree) could be observed in the hybrid and adhesive layers in the control (a). Thickness of silver deposition was over $1 \mu$ m. Sporadic spot-mode silver grains were found in the hybrid layer (b and c). The presence of minimal nanoleakage was manifested in the form of isolated silver grains in the interface of the dry-dentin groups (b, c, and d). B: Bonding resin, D: Dentin, E: Epoxy resin, W: Water tree. 

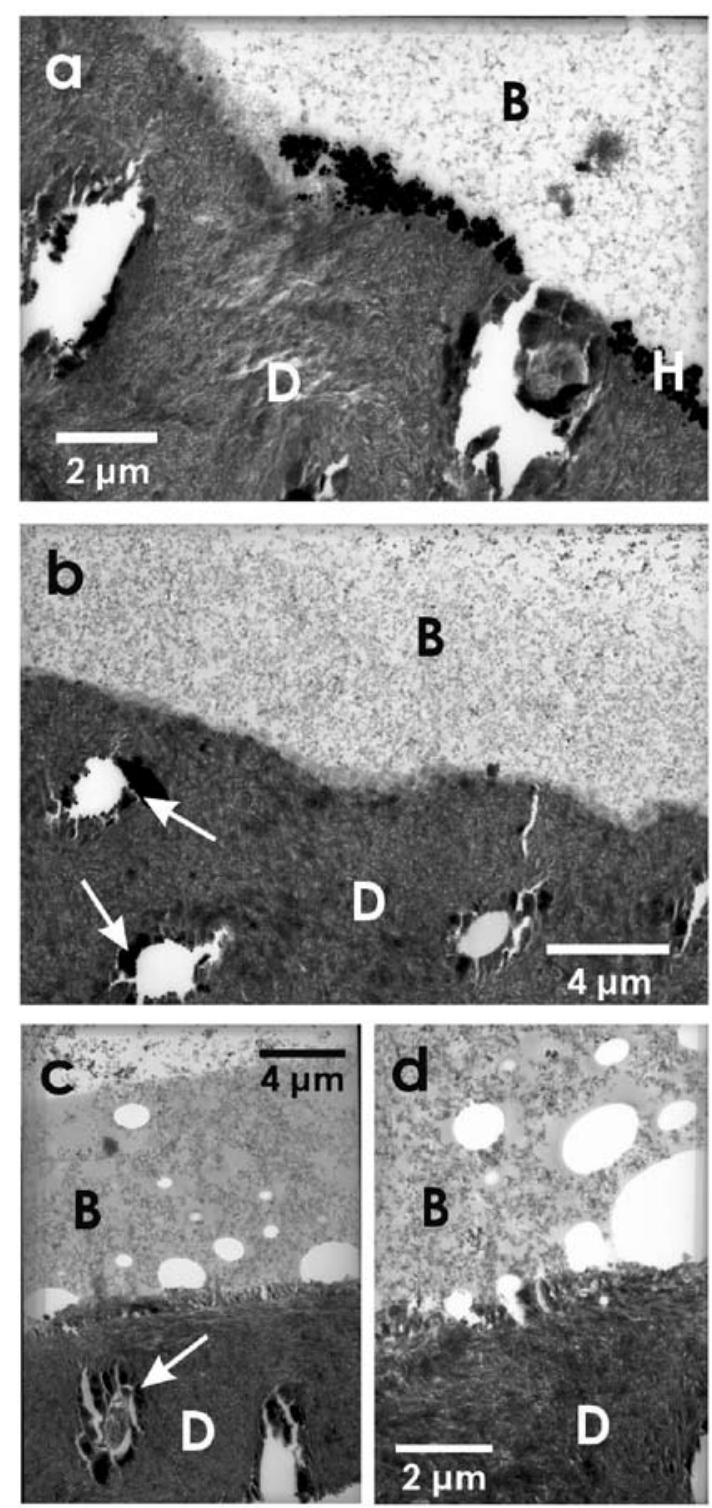

Fig. 4 TEM micrographs of the resin-dentin interface in $\mathrm{S}^{3}$ Bond ( $\left.\mathrm{a}, \mathrm{b}\right)$ and G-Bond specimens (c, d). Sporadic areas of nanoleakage were identified as silver deposits within the hybrid layer in the control (a). There was an overall absence of nanoleakage at the resin-dentin interface of dry dentin in the desiccator (b). For G-Bond, micrometer-sized water bubbles were found in the adhesive layer in the control (c) and dry-dentin specimens in water (d). White arrows indicate silver grains around the dentinal tubules. B: Bonding resin, D: Dentin.

\section{DISCUSSION}

In the present study where both wet bonding and dry bonding techniques were performed on dentin substrates, completely different results were obtained for bond strength and nanoleakage formation. When the bonded specimens were made with dry dentin substrates in dry storage, significantly higher bond strength was obtained with minimal nanoleakage as compared to the wet conditions (control). However, when the specimens of resin-bonded dry dentin were stored in water, bond strength was nearly zero for all the systems (Fig. 1). During rehydration, air-dried human dentin regains its original dimensions when wet again due to water uptake ${ }^{14,15)}$. Therefore, it appeared that water sorption by dry dentin caused an expansion of the dentin substrate, and then further caused debonding between the tooth and the resin composite. Therefore, the null hypothesis that there is no difference in bond strength nor nanoleakage distribution between wet and dry dentin substrates was rejected.

It is well known that nanoleakage occurs in the bonding resin or hybrid layer. The extent of nanoleakage formation correlates with the amount of residual water in the resin-dentin interface after light curing, 1,516-18). Nanoleakage formation arises from two major causes: (1) water contained in the adhesive resin and (2) water diffusing from the dentinal tubules into the adhesive. However, it has not been fully clarified which factor contributes more to nanoleakage formation within resin-dentin bonds. It has been reported that recently marketed adhesives (i.e., all-in-one and one-bottle adhesives) contain increased concentrations of hydrophilic and ionic resin monomers, such that water may be incompletely removed and remain trapped in the resin-dentin interface even after curing. This remnant water could be seen as silver-filled void-like structures via SEM and TEM.

In the current study, the spotted and reticular modes of nanoleakage were minimal in the specimens of the dry-bonding group. With iBond, despite severe nanoleakage in the hybrid or adhesive layer in the control, only minimal nanoleakage (i.e., sporadic spotted mode of nanoleakage expression) was observed in the adhesive layer made with dry dentin. A previous report ${ }^{19)}$ confirmed that water movement immediately occurred across the resin-dentin interface from dentinal tubules during and after bonding. This movement subsequently induced water sorption into the bonding resin. The water sorption of dentin-bonded specimens then increased the elastic buffering effect of the adhesive, leading to decreased contraction stress within 30 minutes after light irradiation ${ }^{20)}$. This initial change seemed to be beneficial for hydrophilic adhesive resin systems, where hydrophilic two-step etch-and-rinse systems showed "contraction-expansion" during the first 30 minutes after light curing.

Based on the results of the current study and those of previous studies ${ }^{19,20)}$, it would seem that the main cause of nanoleakage formation was the presence and continuous supply of water from the 
dentinal tubules or smear layer into the adhesive. Although the residual water from the adhesive was minimal for nanoleakage formation, its hydrophilic nature might render it susceptible to water derived from the bonding substrate (smear layer or dentinal tubules) during bonding. The results also revealed that the water or solvent in the adhesives was effectively evaporated from cured resin by air blasting, a step recommended by each manufacturer following resin application.

It should also be noted that a hydrated dentin surface is essential for wet bonding of etch-and-rinse systems (systems with acid pretreatment) for optimal resin filtration into the collagen web. This would then result in increased bond strength and reduced nanoleakage. However, a hydrated dentin surface poses an adverse effect for hydrophilic self-etching adhesives. We speculated that the water sorption of the adhesive was large for the hydrophilic adhesives used in this study, but might be minimal for hydrophobic resin coatings such as with two-bottle, twostep self-etching systems.

The water bubble formation in G-Bond might be due to phase separation ${ }^{3)}$ as bubbles were seen in all the groups. The round and oval-shaped electronlucent droplets in the bonding resin layer might be due to remnant water from the adhesive, as its composition lacked HEMA. Generally, TEM is a suitable tool for nanoleakage detection, as shown in Figs. 3b and $3 \mathrm{~d}$, because of its high resolution for small silver deposits in comparison with SEM. However, water bubbles created by phase separation usually become relatively large with a diameter ranging from 1 to $10 \mu \mathrm{m}$. Such large droplets can be easily observed by the secondary electron mode of SEM instead of the backscatter mode (Figs. 2a-c.). However, since nanoleakage expression in the form of silver grains was minimal within the interface for the dry-dentin group, the total amount of silver staining of dry bonding was less than that of the control (not shown).

In two-bottle adhesive systems, the primers contain hydrophilic monomers and solvents. The adhesives in the second bottle, on the other hand, are more hydrophobic and which are finally applied over the primer-treated dentin. When primer comonomers are combined with the adhesive constituents in a single bottle or a mixture of two separate bottles, the resulting formulation is relatively hydrophilic. Water sorption of currently available bonding resins reach 1 to 10 mass\%, and this can potentially weaken the mechanical properties of the bonding resin after curing ${ }^{21-23)}$. The different degrees of water sorption and/ or solubility of polymers depend on their mechanical properties and molecular structures ${ }^{22)}$.

The water sorption of hydrophilic resins was found to be significantly higher than that of hydrophobic dental resins ${ }^{23)}$. Therefore, hydrophilic one- bottle adhesives with high water and solvent contents would contribute to a high degree of water sorption. In the present study, this high degree of water sorption further contributed to a large decrease in bond strength in wet dentin (control), as compared to dry bonding. Nonetheless, water sorption might have occurred during the bonding procedure, regardless of whether the resin-bonded specimens were in water or in air after light curing. This was because no clear differences were found in the amount of nanoleakage between the dry-bonded specimens in dry storage or in water, except for a difference in bond strength.

In clinical situations, water sorption/solubility can cause nanoleakage formation or rapid deterioration of the mechanical properties of adhesive resins. In particular, water solubility would decrease the elastic modulus and resistance to wear or flexion ${ }^{24,25)}$, which may slowly degrade the stability of these resin restorations ${ }^{26-33)}$.

\section{ACKNOWLEDGEMENTS}

The materials (G-Bond, GC; iBond, Heraeus Kulzer; and Clearfil $\mathrm{S}^{3}$ Bond, Kuraray) used in this study were generously supplied by the respective manufacturers.

\section{REFERENCES}

1) Tay FR, Pashley DH, Yoshiyama M. Two modes of nanoleakage expression in single-step adhesives. J Dent Res 2002; 7: 472-476.

2) Spencer P, Wang Y. Adhesives phase separation at the dentin interface under wet bonding conditions. J Biomed Mater Res 2002; 62: 447-456.

3) Van Landuyt K, De Munck J, Snauwaert J, Coutinho E, Poitevin A, Yoshida Y, Inoue S, Peumans M, Suzuki K, Lambrechts P, Van Meerbeek B. Monomer-solvent phase separation in one-step selfetch adhesives. J Dent Res 2005; 84: 183-188.

4) Hashimoto M, Ohno H, Sano H, Kaga M, Oguchi H. In vitro degradation of resin-dentin bonds analyzed by microtensile bond test, scanning and transmission electron microscopy. Biomater 2003; 24: 37953803.

5) Tay FR, King NM, Chan KM, Pashley DH. How can nanoleakage occur in self-etching adhesive systems that demineralize and infiltrate simulatenously? J Adhes Dent 2002; 4: 255-269.

6) Lai SCN, Tay FR, Cheung GSP, Mak YF, Carvalho RM, Wei SHY, Toledano M, Osorio R, Pashley DH. Reversal of compromised bonding in bleached enamel. J Dent Res 2002; 81: 477-481.

7) Tay FR, Pashley DH, Suh BI, Carvalho RM, Itthagarun A. Single-step adhesives are permeable membranes. J Dent 2002; 30: 371-382.

8) Hashimoto M, Tay FR, Ito S, Sano H, Kaga M, Pashley DH. Permeability of adhesive resin films. J Biomed Mater Res 2005; 74: 699-706.

9) Tay FR, Pashley DH, Hiraishi N, Imazato S, 
Rueggeberg FA, Salz U, Zimmermann J, King NM. Tubular occlusion prevents water-tree and throughand-through fluid movement in a single-bottle, onestep self-etch adhesive model. J Dent Res 2005; 84: 891-896.

10) Yoshida E, Uno S, Nodasaka Y, Kaga M, Hirano S. Relationship between water status in dentin and interfacial morphology in all-in-one adhesives. Dent Mater 2007; 23: 556-560.

11) Carvalho RM, Tay FR, Giannini M, Pashley DH. Effects of pre- and post-bonding hydration on bond strength to dentin. J Adhes Dent 2004; 6: 13-17.

12) Perdigão J, Lambrechts $P$, Van Meerbeek B, Vanherle G, Lopes AL. Field emission SEM comparison of four postfixation drying techniques for human dentin. J Biomed Mater Res 1995; 29: 11111120 .

13) Tay FR, Pashley DH. Water-treeing - a potential mechanism for degradation of dentin adhesives. Am J Dent 2003; 16: 6-12.

14) van der Graaf ER, ten Bosch JJ. The uptake of water by freeze-dried human dentine sections. Archs Oral Biol 1990; 35: 731-739.

15) van der Graaf ER, ten Bosch JJ. Changes in dimensions and weight of human dentin after different drying procedures and during subsequent rehydration. Archs Oral Biol 1993; 38: 97-99.

16) Yiu CKY, King NM, Pashley DH, Suh BI, Carvalho RM, Carrilho MR, Tay FR. Effect of resin hydrophilicity and water storage on resin strength. Biomater 2004; 25: 5789-5796.

17) Hiraishi N, Nishiyama N, Ikemura K, Yau JYY, King NM, Tagami J, Pashley DH, Tay FR. Water concentration in self-etching primers affects their aggressiveness and bonding efficacy to dentin. J Dent Res 2005; 84: 653-658.

18) Nishitani Y, Yoshiyama M, Donnelly AM, Agee KA, Sword J, Tay FR, Pashley DH. Effect of resin hydrophilicity on dentin bond strength. J Dent Res 2006; 85: 1016-1021.

19) Hashimoto M, Ito S, Tay FR, Svizero NR, Sano H, Kaga M, Pashley DH. Fluid movement across the resin-dentin interface during and after bonding. J Dent Res 2004; 83: 843-848.

20) Hashimoto M, de Gee AJ, Kaga M, Feilzer AJ. Contraction stress in dentin adhesives bonded to dentin. J Dent Res 2006; 85: 728-732.

21) Burrow MF, Inokoshi S, Tagami J. Water sorption of several bonding resins. Am J Dent 1999; 12: 295298.
22) Mortier E, Gerdolle DA, Jacquot B, Panighi MM. Importance of water sorption and solubility studies for couple bonding agent - resin-based filling material. Oper Dent 2004; 29: 669-676.

23) Ito S, Hashimoto M, Wadgaonka B, Svizero N, Carvalho RM, Yiu CK, Rueggeberg, FA, Foulger S, Saito T, Nishitani Y, Yoshiyama M, Tay FR, Pashley DH. Effects of resin hydrophilicity on water sorption and changes in modulus of elasticity. Biomater 2005; 26: 6449-6459.

24) Cattani-Lorente MA, DuPuis V, Payan J, Moya F, Meyer JM. Effect of water on the physical properties of resin-modified glass-ionomer cements. Dent Mater 1999; 15: 71-78.

25) Musanje L, Shu M, Darvell BW. Water sorption and mechanical behavior of cosmetic direct restorative materials in artificial saliva. Dent Mater 2001; 17: 394-401.

26) Sano H, Yoshikawa T, Pereira PNR, Kanemura N, Morigami M, Tagami J, Pashley DH. Long-term durability of dentin bonds made with a self-etching primer, in vivo. J Dent Res 1999; 78: 906-911.

27) Tanaka J, Ishikawa K, Yatani H, Yamashita A, Suzuki K. Correlation of dentin bond durability with water absorption of bonding layer. Dent Mater J 1999; 18: 11-18.

28) Hashimoto M, Ohno H, Kaga M, Endo K, Sano H, Oguchi $\mathrm{H}$. In vivo degradation of resin-dentin bonds in humans over 1 to 3 years. J Dent Res 2000; 79: 1385-1391.

29) De Munck Y, Van Meerbeek B, Yoshida Y, Inoue S, Vargas M, Suzuki K, Lambrechts P, Vanherle G. Four-year water degradation of total-etch adhesives bonded to dentin. J Dent Res 2003; 82: 136-140.

30) Tay FR, Hashimoto M, Pashley DH, Peters MC, Lai SCN, Yiu CKY, Cheong C. Aging affects two modes of nanoleakage expression in bonded dentin. J Dent Res 2003; 82: 537-541.

31) Donmez N, Belli S, Pashley DH, Tay FR. Ultrastructural correlates of in vivo/in vitro bond degradation in self-etch adhesives. J Dent Res 2005; 84: 355-359.

32) Carrilho MR, Carvalho RM, de Goes MF, di Hipolito V, Geraldeli S, Tay FR, Pashley DH, Tjaderhane L. Chlorhexidine preserves dentin bond in vitro. J Dent Res 2007; 86: 90-94.

33) Hashimoto M, Fujita S, Kaga M, Yawaka Y. In vitro durability of one-bottle resin adhesives bonded to dentin. Dent Mater J 2007; 26: 677-686. 